\title{
Basolateral Amygdala Noradrenergic Influences on Memory Storage Are Mediated by an Interaction between $\beta$ - and $\alpha_{1}$-Adrenoceptors
}

\author{
Barbara Ferry, Benno Roozendaal, and James L. McGaugh \\ Center for the Neurobiology of Learning and Memory and Department of Neurobiology and Behavior, University of \\ California, Irvine, California 92697-3800
}

\begin{abstract}
Extensive evidence indicates that norepinephrine modulates memory storage through an activation of $\beta$-adrenoceptors in the basolateral nucleus of the amygdala (BLA). Recent findings suggest that the effects of $\beta$-adrenergic activation on memory storage are influenced by $\alpha_{1}$-adrenoceptor stimulation. Pharmacological findings indicate that activation of postsynaptic $\alpha_{1}$-adrenoceptors potentiates $\beta$-adrenoceptor-mediated activation of cAMP formation. The present study examined whether inactivation of $\alpha_{1}$-adrenoceptors in the BLA would alter the dose-response effects on memory storage of intra-BLA infusions of a $\beta$-adrenoceptor agonist, as well as that of a synthetic cAMP analog. Male Sprague Dawley rats received bilateral microinfusions into the BLA of either the $\beta$-adrenoceptor agonist clenbuterol $(3-3000 \mathrm{pmol}$ in $0.2 \mu \mathrm{l})$ or 8 -bromoadenosine $3^{\prime}: 5^{\prime}$-cyclic monophosphate (8-bromo-cAMP) $(0.2-7 \mathrm{nmol}$ in $0.2 \mu \mathrm{l})$ alone or together with the $\alpha_{1}$-adrenoceptor antagonist prazosin $(0.2 \mathrm{nmol})$ immediately after training in an inhibitory
\end{abstract}

Several lines of evidence suggest that the storage of information for inhibitory avoidance training is regulated by $\beta$-adrenergic influences within the amygdaloid complex (McGaugh et al., 1993). Posttraining infusions of norepinephrine or the $\beta$-adrenoceptor agonist clenbuterol into the amygdala enhance memory storage (Liang et al., 1990; Introini-Collison et al., 1991). More recent findings from our laboratory suggest that the memory-modulatory effects of the $\beta$-adrenoceptor system of the amygdala are mediated selectively by the basolateral nucleus of the amygdala (BLA). Infusions of $\beta$-adrenoceptor antagonists administered into the BLA, and not the central nucleus $(\mathrm{CN})$, block the memory-enhancing effects of posttraining systemic injections of glucocorticoids (Quirarte et al., 1997). Posttraining infusions of norepinephrine or the $\beta$-adrenoceptor agonist clenbuterol into the BLA enhance retention of inhibitory avoidance and water-maze training (Ferry and McGaugh, 1999; Hatfield and McGaugh, 1999).

Other recent findings from our laboratory indicate that the noradrenergic influence on memory storage also involves activa-

\footnotetext{
Received Dec. 17, 1998; revised March 24, 1999; accepted March 30, 1999.

This research was supported by a FYSSEN Foundation grant and a fellowship from the Ralph and Leona Gerard Family Trust (B.F. and B.R.) and United States Public Health Service Grant MH12526 from National Institute of Mental Health (J.L.M.). We thank Jimmy Nong for technical assistance and Nancy Collett for assistance in the preparation of this manuscript.

Correspondence should be addressed to Dr. Barbara Ferry, Center for the Neurobiology of Learning and Memory, University of California, Irvine, CA 926973800 .

Copyright (C) 1999 Society for Neuroscience $\quad 0270-6474 / 99 / 195119-05 \$ 05.00 / 0$
}

avoidance task. Retention was tested $48 \mathrm{hr}$ later. Clenbuterol induced a dose-dependent enhancement of retention, and prazosin attenuated the dose-response effects of clenbuterol. Posttraining intra-BLA infusions of 8-bromo-cAMP also induced a dose-dependent enhancement of retention latencies. However, concurrent infusion of prazosin did not alter the doseresponse effects of 8-bromo-cAMP. These findings are consistent with the view that $\alpha_{1}$-adrenoceptors affect memory storage by modulating $\beta$-adrenoceptor activation in the BLA. Moreover, these findings are consistent with those of pharmacological studies indicating that $\beta$-adrenoceptors modulate memory storage by a direct coupling to adenylate cyclase, whereas $\alpha_{1}$ receptors act indirectly by influencing the $\beta$-adrenoceptormediated influence on CAMP formation.

Key words: basolateral amygdala; $\alpha_{1}$-adrenoceptor; $\beta$-adrenoceptor; norepinephrine; memory storage; cAMP tion of $\alpha_{1}$-adrenoceptors. Posttraining infusions of the selective $\alpha_{1}$-adrenoceptor antagonist prazosin administered into the BLA impair inhibitory avoidance retention, whereas selective activation of $\alpha_{1}$-adrenoceptors enhances retention (Ferry et al., 1999). Furthermore, the memory-modulatory effects of norepinephrine in the BLA appear to be mediated by an interaction between $\alpha_{1}$ and $\beta$-adrenoceptors. Posttraining infusions of the $\beta$-adrenoceptor antagonist atenolol into the BLA block the memory enhancement induced by selective $\alpha_{1}$-adrenoceptor activation (Ferry et al., 1999). These results suggest that the role of the $\alpha_{1}$ adrenoceptor system in regulating memory storage involves modulation of $\beta$-adrenergic activity. These findings are consistent with evidence that $\alpha_{1}$ - and $\beta$-adrenoceptors interact in modulating catecholamine-induced physiological responses in the rat brain (Perkins and Moore, 1973; Schultz and Daly, 1973; Stone et al., 1987).

It is known that the generation of second messengers, such as cAMP, permits the distribution of cell-surface regulatory input within the cell interior, amplification of the initial signal, and enables synergistic or antagonistic regulation of other signaling pathways. Norepinephrine has been shown to increase cAMP levels in brain tissue (Burkard, 1972), an effect involving an interaction between $\beta$ - and $\alpha_{1}$-adrenoceptors (Rall and Sattin, 1970; Huang and Daly, 1972; Schultz and Daly, 1973). The $\beta$-adrenoceptor is coupled directly to adenylate cyclase via the guanine-nucleotide-binding regulatory Gs protein (Pfeuffer, 1977; Ross et al., 1978), whereas the $\alpha_{1}$-adrenoceptor site appears to be indirectly coupled to the cAMP-generating system by po- 
tentiating the response induced by $\beta$-adrenoceptor activation (Perkins and Moore, 1973; Daly et al., 1980).

The present study examined further the interaction of $\beta$ - and $\alpha_{1}$-adrenoceptor activation in the BLA and the coupling to the cAMP system in memory storage. A first experiment examined the functional interaction between the two receptor types in regulating memory storage. Rats received microinf usions of clenbuterol, a $\beta$-adrenoceptor agonist, alone or together with the $\alpha_{1}$-adrenoceptor antagonist prazosin into the BLA immediately after training in an inhibitory avoidance task. A second experiment investigated whether the influence of $\alpha_{1}$-adrenoceptors on memory occurs before or after the $\beta$-adrenoceptor-mediated cAMP formation. To address this issue, the effects of posttraining intra-BLA infusions of 8-bromoadenosine $3^{\prime}: 5^{\prime}$-cyclic monophosphate (8-bromo-cAMP) (an analog of cAMP that passes the cell membrane) were examined when administered alone or together with prazosin.

\section{MATERIALS AND METHODS}

Subjects. Male Sprague Dawley rats ( $n=254$; body weight, $270-300 \mathrm{gm}$ at the time of surgery) from Charles River Laboratories (Wilmington, MA) were used. After arrival, they were individually housed in a temperature-controlled $\left(22^{\circ} \mathrm{C}\right)$ colony room and maintained on a standard $12 \mathrm{hr}$ light/dark cycle (lights on from 7:00 A.M. to 7:00 P.M.) with access to food and water ad libitum. All experiments were performed during the light phase of the cycle between 10:00 A.M. and 2:00 P.M..

Surgery. One week after arrival, the animals were anesthetized with sodium pentobarbital $(50 \mathrm{mg} / \mathrm{kg}$ body weight, i.p.) and given atropine sulfate $(0.4 \mathrm{mg} / \mathrm{kg}$, i.p.) to suppress salivation. The skull was fixed in a flat position to a stereotaxic frame (Kopf Instruments, Tujunga, CA), and stainless steel cannulas (23 gauge, $15 \mathrm{~mm}$ long) were implanted bilaterally $2 \mathrm{~mm}$ dorsal to the BLA (coordinates: anteroposterior, $-2.8 \mathrm{~mm}$ from bregma; mediolateral, $\pm 5.0 \mathrm{~mm}$ from midline; dorsoventral, -6.7 $\mathrm{mm}$ from skull surface) according to the atlas of Paxinos and Watson (1986). The cannulas and two anchoring screws were affixed to the skull with dental cement. Stylets (15-mm-long 00 insect dissection pins) were inserted into each cannula to maintain patency and were removed only for the infusion of drugs. The rats were allowed to recover a minimum of $7 \mathrm{~d}$ and were handled $1 \mathrm{~min}$ each day for 3 consecutive days before training was initiated.

Drugs and infusion procedures. Clenbuterol (4-amino-a-[t-butylaminomethyl]-3,5-dichlorobenzyl alcohol hydrochloride; Sigma, St. Louis, $\mathrm{MO})$, a selective $\beta_{1}$-adrenoceptor agonist, prazosin (1-[4-amino-6,7dimethoxy-2-quinazolinyl]-4-[2-furanylcarbonyl] piperazine; Sigma), a selective $\alpha_{1}$-adrenoceptor antagonist, and 8-bromo-cAMP (Sigma) were used. The compounds were dissolved in $0.9 \%$ saline. Control animals received saline only. Clenbuterol $(3,30,300$, or $3000 \mathrm{pmol} / \mathrm{side})$ and 8 -bromo-cAMP $(0.2,0.7,2$, or $7 \mathrm{nmol} /$ side $)$ were infused alone or in combination with prazosin $(0.2 \mathrm{nmol})$ into the BLA immediately after the training session. The doses of clenbuterol and prazosin were selected on the basis of previous experiments (Liang et al., 1995; Ferry and McGaugh, 1999), whereas the doses of 8-bromo-cAMP were selected from a recent study by Bernabeu and colleagues (1997). Solutions of all drugs were prepared freshly before each experiment. Bilateral intra-BLA inf usions of saline or drug were made using 30 gauge injection needles connected to a $10 \mu \mathrm{l}$ Hamilton microsyringe by polyethylene (PE 20) tubing. The injection needles protruded $2 \mathrm{~mm}$ beyond the tips of the cannulas to reach the BLA. A $0.2 \mu$ l injection volume per side was infused for $23 \mathrm{sec}$ by an automated syringe pump (Sage Instruments, Boston, MA). To allow diffusion of the drug, the injection needles were retained within the cannulas for an additional $50 \mathrm{sec}$ after drug infusion. The infusion volume was based on our findings that selective neurotoxically induced lesions of the BLA are produced with an infusion volume of $0.2 \mu \mathrm{l}$ (Roozendaal and McGaugh, 1996). Furthermore, drug infusions of this volume into either the BLA or the adjacent $\mathrm{CN}$ induce markedly differential effects on memory storage (Parent and McGaugh, 1994; Roozendaal and McGaugh, 1997). After infusion, the animal was returned to its home cage.

Inhibitory avoidance apparatus and procedures. The inhibitory avoidance apparatus consisted of a trough-shaped alley $(91 \mathrm{~cm}$ long, $15 \mathrm{~cm}$ deep, $20 \mathrm{~cm}$ wide at the top, $6.4 \mathrm{~cm}$ wide at the floor) divided into two

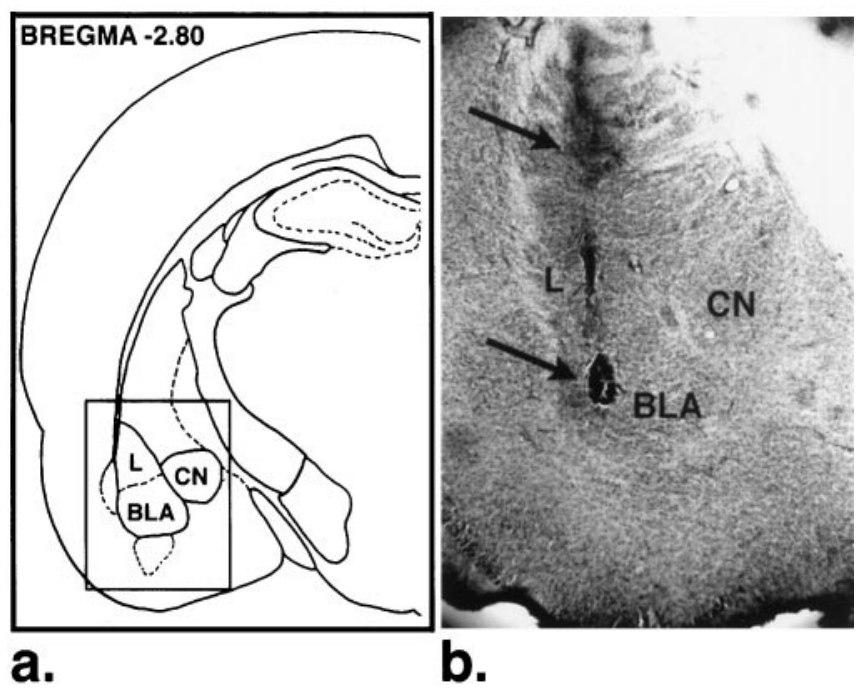

Figure 1. a, Schematic representation of the amygdaloid complex. The solid lines indicate the position of the photomicrograph $(b)$ representing the cannula (top arrow) and the injection tip (bottom arrow) placement. $L$, Lateral nucleus of the amygdala.

compartments separated by a sliding door that opened by retracting into the floor. The starting compartment (31 cm long) was illuminated, and the shock compartment (60 cm long) was dark (McGaugh et al., 1988). The apparatus was located in a light- and sound-attenuated room.

The rat was placed in the starting compartment, with the door opened, and was allowed to enter the dark compartment. After the rat stepped completely into the dark compartment, the door was closed, and a mild inescapable foot shock $(0.40 \mathrm{~mA}, 1.0 \mathrm{sec})$ was administered. Animals with entrance latencies longer than $30 \mathrm{sec}$ were eliminated from the study. The rat was removed from the dark alley $15 \mathrm{sec}$ after termination of the foot shock and immediately given bilateral microinf usions of either saline or drug into the BLA. On the $48 \mathrm{hr}$ retention test, the rat was placed in the starting compartment, as in the training session, and the latency to enter the dark compartment (maximum latency of $600 \mathrm{sec}$ ) was recorded and used as the measure of retention. Shock was not administered on the retention test trial.

Histology. After completion of behavioral testing, the rats were anesthetized with an overdose of sodium pentobarbital $(100 \mathrm{mg} / \mathrm{kg})$ and perfused intracardially with a $0.9 \%$ saline $(\mathrm{w} / \mathrm{v})$ solution, followed by $4 \%$ formaldehyde $(\mathrm{w} / \mathrm{v})$. After decapitation, the brains were removed and placed in $4 \%$ formaldehyde. At least $24 \mathrm{hr}$ before sectioning, the brains were placed in a $15 \%$ sucrose $(\mathrm{w} / \mathrm{v})$ solution for cryoprotection. Sections of $40 \mu \mathrm{m}$ were made (using a freezing microtome) and stained with cresyl violet. The sections were examined under a light microscope, and determination of the location of cannula tips in the BLA was made according to the standardized atlas plates of Paxinos and Watson (1986).

Statistics. Retention data were analyzed with two-way ANOVAs with clenbuterol (five levels) or 8-bromo-cAMP (five levels) and prazosin (two levels), both as between-subject variables. Further analysis used Fisher's post hoc tests to determine the source of the detected significances in the ANOVAs. A probability level of $<0.05$ was accepted as statistically significant. The number of animals per group is indicated in the figure legends.

\section{RESULTS}

Figure 1 shows a representative location of the inf usion needle tip in the BLA. Behavioral data from 228 animals were included in the analysis. Histological analysis revealed that 26 animals had incorrect cannula placements. The results of these animals were not included in the analyses.

The retention test latencies of rats given posttraining infusions of one of several doses of clenbuterol alone or in combination with prazosin into the BLA are shown in Figure 2. A two-way ANOVA revealed a significant clenbuterol effect $\left(F_{(4,99)}=8.71\right.$; 


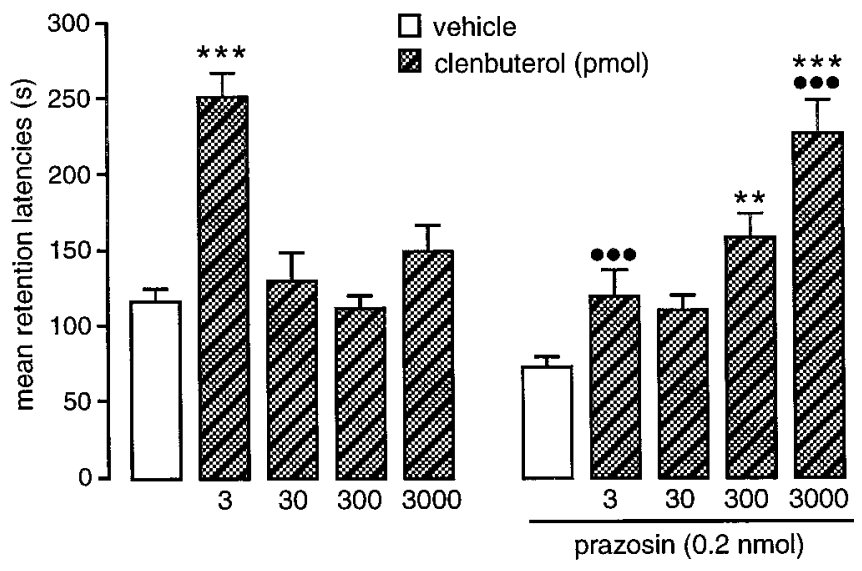

Figure 2. Inhibitory avoidance retention latencies of animals that received posttraining infusion of several doses of the selective $\beta$-adrenoceptor agonist clenbuterol alone or in combination with the selective $\alpha_{1}$-adrenoceptor antagonist prazosin into the BLA. Error bars represent mean \pm SEM latency (in seconds) to enter the dark compartment on the retention test. ${ }^{* *} p<0.01$; ${ }^{* *} p<0.001$ compared with vehicle-infused group; $\bullet \bullet p<0.001$ compared with the corresponding groups infused with clenbuterol alone. $n=9-12$ per group.

$p<0.001)$ and a significant interaction between clenbuterol and prazosin $\left(F_{(4,99)}=11.21 ; p<0.001\right)$. Clenbuterol enhanced retention latencies when inf used in the lowest dose only ( $3 \mathrm{pmol}$; $p<0.001)$ compared with the saline controls. Inf usion of higher doses of clenbuterol $(30,300$, and 3000 pmol) had no significant effect on retention. Concurrent infusions of prazosin into the BLA shifted the dose-response effects of clenbuterol to the right. The retention-enhancing effect observed with the infusion of 3 pmol of clenbuterol was blocked by prazosin $(p<0.001)$. In prazosin-treated animals, significant increases in retention latencies were found with inf usions of higher doses of clenbuterol (300 and 3000 pmol; both, $p<0.001)$.

The retention test latencies of rats given posttraining intraBLA infusions of various doses of 8-bromo-cAMP alone or in combination with prazosin are shown in Figure 3. A two-way ANOVA revealed a significant 8-bromo-cAMP effect $\left(F_{(4,109)}=\right.$ $11.46 ; p<0.001)$ but no prazosin effect $\left(F_{(1,109)}=0.70 ; \mathrm{NS}\right)$ or interaction between the two factors $\left(F_{(4,109)}=0.66 ; \mathrm{NS}\right)$. 8-Bromo-cAMP enhanced retention latencies when infused in the lowest dose only $(0.2 \mathrm{nmol} ; p<0.001)$ compared with the controls. Infusion of the higher doses of 8-bromo-cAMP $(0.7,2$, and $7 \mathrm{nmol}$ ) were ineffective. Concurrent infusions of prazosin into the BLA did not alter the dose-response effects of 8-bromocAMP on memory storage. The same low dose of 8-bromocAMP (0.2 nmol) enhanced retention latencies when infused either alone or together with prazosin $(p<0.001)$.

\section{DISCUSSION}

There are two main findings of these experiments. First, they provide further evidence that $\beta$ and $\alpha_{1}$ components of the adrenoceptor system in the BLA are involved in modulating memory storage. Second, infusions of the second messenger cAMP analog 8-bromo-cAMP into the BLA enhanced inhibitory avoidance retention performance, and the effect of infusions of 8-bromocAMP on memory does not depend on $\alpha_{1}$-adrenoceptor activity. These findings clearly suggest that the effect of $\alpha_{1}$-adrenoceptors on memory occurs at the level of the $\beta$-adrenoceptor-mediated cAMP generation.

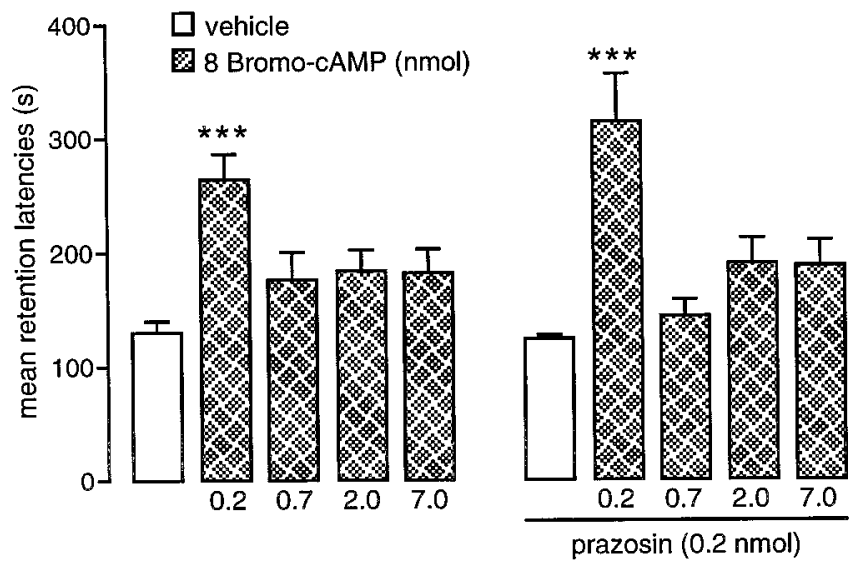

Figure 3. Inhibitory avoidance retention latencies of animals that received posttraining infusion of several doses of 8-bromo-cAMP, an analog of cAMP that passes the cell membrane, alone or in combination with the selective $\alpha_{1}$-adrenoceptor antagonist prazosin into the BLA. Error bars represent mean \pm SEM latency (in seconds) to enter the dark compartment on the retention test. $* * * p<0.001$ compared with vehicleinfused group. $n=10-13$ per group.

The results of the first experiment indicate that the memorymodulatory effects of $\beta$-adrenoceptors in the BLA are mediated by an interaction with $\alpha_{1}$-adrenoceptors. The finding that prazosin blocked the memory-enhancing effect induced by a low dose of clenbuterol and attenuated its dose-response effects clearly suggests that $\alpha_{1}$-adrenoceptors in the BLA influence the effect of $\beta$-adrenoceptor activation on memory storage. These findings are in agreement with extensive evidence indicating that activation of $\beta$-adrenergic mechanisms in the amygdala (in particular in the BLA) induces dose-dependent memory enhancement (Liang et al., 1986, 1990; Introini-Collison et al., 1989, 1991; Ferry and McGaugh, 1999; Hatfield and McGaugh, 1999). These findings are also in agreement with evidence implicating $\alpha_{1}$-adrenergic mechanisms in memory consolidation processes. Sternberg et al. (1986) reported that pretraining systemic injections of the nonselective $\alpha$-adrenoceptor antagonist phentolamine attenuated the memory-enhancing effect of peripherally administered epinephrine. Puumala et al. (1998) found that pretraining stimulation of $\alpha_{1}$-adrenoceptors facilitates acquisition of the water-maze task. Furthermore, our results are consistent with evidence suggesting an involvement of amygdala $\alpha$-adrenoceptors in the influence of norepinephrine on memory storage. Gallagher and Kapp (1981) found that posttraining infusions of various doses of the nonselective $\alpha$-adrenoceptor antagonist phentolamine into the amygdala induced a dose-dependent enhancement of retention latencies in an inhibitory avoidance task. The inverted U-shaped curve of retention latencies suggests that $\alpha_{2}$ - and $\alpha_{1}$-adrenoceptors (both present in the amygdala; U'Prichard et al., 1980) may be differentially involved in modulating memory storage. At low doses, phentolamine enhances norepinephrine activity by facilitating its release through blockade of presynaptic $\alpha_{2^{-}}$ adrenoceptors (Starke, 1979). At higher doses, phentolamine also acts on postsynaptic $\alpha_{1}$-adrenoceptors. More recently, we reported that the memory-enhancing effects induced by selective activation of $\alpha_{1}$-adrenoceptors in the BLA were blocked by a concomitant infusion of the $\beta$-adrenoceptor antagonist atenolol (Ferry et al., 1999). These results suggest that $\alpha_{1}$-adrenoceptorinduced retention enhancement involves $\beta$-adrenoceptor activation. Our present findings, considered together with previous 
results, thus suggest that $\alpha_{1}$-adrenoceptors are indirectly involved in modulating memory storage by influencing $\beta$-adrenoceptor activation.

Several pharmacological findings suggest that $\alpha$ - and $\beta$-adrenoceptors are present on the same neurons (Szabadi and Bradshaw, 1974; Bevan et al., 1977; Szabadi, 1978). In addition, $\beta$-adrenoceptor stimulation increases intracellular cAMP levels via a direct activation of adenylate cyclase (Schultz and Daly, 1973; Taussig and Gilman, 1995). $\alpha_{1}$-Adrenoceptors are not coupled to adenylate cyclase but modulate cAMP release indirectly by potentiating $\beta$-adrenoceptor-cAMP responsiveness (Perkins and Moore, 1973; Daly et al., 1980, 1981; Leblanc and Ciaranello, 1984; Johnson and Minneman, 1986; Pilc and Enna, 1986). In view of these findings, the second experiment addressed the locus of interaction between the $\beta$ - and $\alpha_{1}$-adrenoceptors in the BLA. Posttraining infusions of 8-bromo-cAMP into the BLA dosedependently enhanced retention, suggesting that the second messenger cAMP in the BLA is involved in inhibitory avoidance memory storage. This finding is in general agreement with previous results showing that posttraining infusions of 8-bromocAMP into the hippocampus or the amygdala enhanced retention in the inhibitory avoidance task (Liang et al., 1995; Bernabeu et al., 1996, 1997). In addition, concurrent administration of prazosin did not alter the memory-enhancing effect of 8-bromo-cAMP. This finding provides evidence concerning the interaction between $\beta$ - and $\alpha_{1}$-adrenoceptors and rules out the possibility that the $\alpha_{1}$-adrenoceptor modulates memory storage by acting downstream from cAMP synthesis in the BLA. If that were the case, infusions of prazosin should have attenuated the dose-response effects of 8-bromo-cAMP. The lack of effect induced by prazosin suggests that $\alpha_{1}$-adrenoceptors influence $\beta$-adrenoceptormediated effects on memory by acting upstream from cAMP formation.

Although these findings are consistent with pharmacological evidence indicating a direct interaction between postsynaptic $\alpha_{1}$ and $\beta$-adrenoceptors in cAMP synthesis, the lack of effect of prazosin on the dose-response curve of 8-bromo-cAMP might also reflect an indirect participation of the $\alpha_{1}$-adrenoceptors in the $\beta$-mediated memory storage modulation. It is possible that the role of the $\alpha_{1}$-adrenoceptors in memory storage is independent of the $\beta$-mediated cAMP generation and might interact with $\beta$-adrenoceptors via another intracellular route (Hardman et al., 1997). Furthermore, although findings of several experiments have reported colocalization of $\beta$ - and $\alpha_{1}$-adrenoceptors in brain neurons (for review, see Szabadi, 1979), it cannot be excluded that the effects induced by clenbuterol and prazosin are mediated by an interaction between $\beta$ - and $\alpha_{1}$-adrenoceptors located on different cells in the BLA. The presence of $\beta$ - and $\alpha_{1}$-adrenoceptors on astroglial cells (McCarty and De Vellis, 1979; Hosli et al., 1982) may be of significance in the regulation of the response to norepinephrine released from neurons (for review, see Salm and McCarthy, 1992). Although the role of these receptors is likely to induce differentiation leading to morphological changes of the cell (Shain et al., 1987; Bicknell et al., 1989), it is reasonable to think that these receptors might also participate in the effects observed in our study. These alternative explanations of the present findings are highly speculative but cannot be excluded as yet.

In conclusion, our results indicate that memory storage of inhibitory avoidance training is modulated by an interaction between $\beta$ - and $\alpha_{1}$-adrenoceptors in the BLA. Moreover, the present findings suggest that the memory enhancement induced by $\beta$-receptor activation in the BLA is mediated by cAMP generation and that this process is modulated by $\alpha_{1}$-adrenoceptor stimulation.

\section{REFERENCES}

Bernabeu R, Schmitz P, Faillance MP, Izquierdo I, Medina JH (1996) Hippocampal cGMP and cAMP are differentially involved in memory processing of inhibitory avoidance learning. NeuroReport 7:585-588.

Bernabeu R, Bevilaqua L, Ardenghi P, Bromberg E, Schmitz P, Bianchin M, Izquierdo I, Medina JH (1997) Involvement of hippocampal cAMP/cAMP-dependent protein kinase signaling pathways in a late memory consolidation phase of aversively motivated learning in rats. Proc Natl Acad Sci USA 94:7041-7046.

Bevan P, Bradshaw CM, Szabadi E (1977) The pharmacology of adrenergic neuronal responses in the cerebral cortex: evidence for excitatory $\alpha$ - and inhibitory $\beta$-receptors. Br J Pharmacol 59:635-641.

Bicknell RJ, Luckman SM, Inenaga K, Mason WT, Hatton GI (1989) $\beta$-adrenergic and opioid receptors on pituicytes cultured from adult rat neurophyophysis: regulation of cell morphology. Brain Res Bull 22:379-388.

Burkard WP (1972) Catecholamines induced increase of cyclic adenosine $3^{\prime}, 5^{\prime}$-monophosphate in rat brain in vivo. J Neurochem 19:2615-2619.

Daly JW, Padgett W, Nimitkitpaisan, Y, Creveling CR, Cantacuzene D, Kirk KL (1980) Fluoronorepinephrine specific agonists for the activation of $\alpha$ and $\beta$ adrenergic-sensitive cyclic AMP-generating systems in brain slices. J Pharmacol Exp Ther 212:382-389.

Daly JW, Padgett W, Creveling CR, Cantacuzene D, Kirk KL (1981) Cyclic AMP-generating systems: regional differences in activation by adrenergic receptors in rat brain. J Neurosci 1:49-59.

Ferry B, McGaugh JL (1999) Clenbuterol administration into the basolateral amygdala posttraining enhances retention in an inhibitory avoidance task. Neurobiol Learn Mem, in press.

Ferry B, Roozendaal B, McGaugh JL (1999) Involvement of $\alpha_{1}$ adrenergic receptors in the basolateral amygdala in modulation of memory storage. Eur J Pharmacol, in press.

Gallagher M, Kapp BS (1981) Effect of phentolamine administration into the amygdala complex of rats on time-dependent memory processes. Behav Neural Biol 31:90-95.

Hardman JG, Limbird LE, Molinoff PB, Ruddon RW, Gilman AG, (1997) Catecholamines and sympathometic drugs: endogeneous catecholamines. In: The pharmacological basis of therapeutics (Goodman LS, Gilman A, eds), pp 204-248. New York: McGraw-Hill.

Hatfield T, McGaugh JL (1999) Norepinephrine infused into the basolateral amygdala posttraining enhances retention in a spatial water maze task. Neurobiol Learn Mem 71:232-239.

Hosli L, Hosli E, Zehntnor C, Lehmann R, Lutz TW (1982) Evidence for the existence of $\alpha$ - and $\beta$-adrenoceptors on cultured glial cells: an electrophysiological study. Neuroscience 7:2867-2872.

Huang M, Daly J (1972) Accumulation of cyclic adenosine monophosphate in incubated slices of brain tissue. Structure-activity relationship of agonists of biogenic amines and tricyclic tranquilizers and antidepressants. J Med Chem 15:458-462.

Introini-Collison IB, Nagahara AH, McGaugh JL (1989) Memoryenhancement with intra-amygdala posttraining naloxone is blocked by concurrent administration of propranolol. Brain Res 476:94-101.

Introini-Collison IB, Miyazaki B, McGaugh JL (1991) Involvement of the amygdala in the memory-enhancing effects of clenbuterol. Psychopharmacology 104:541-544.

Johnson RD, Minneman KP (1986) Characterization of $\alpha 1$-adrenergic receptors which increase cyclic AMP accumulation in rat cerebral cortex. Eur J Pharmacol 129:293-300.

Leblanc GG, Ciaranello RD (1984) $\alpha$-Noradrenergic potentiation of neurotransmitter-stimulated cAMP production in rat striatal slices. Brain Res 293:57-65.

Liang KC, Juler RG, McGaugh JL (1986) Modulating effects of posttraining epinephrine on memory: involvement of the amygdala noradrenergic system. Brain Res 368:125-133.

Liang KC, McGaugh JL, Yao HY (1990) Involvement of the amygdala pathways in the influence of post-training intra-amygdala norepinephrine and peripheral epinephrine on memory storage. Brain Res 508:225-233.

Liang KC, Chen LL, Huang TE (1995) The role of amygdala norepinephrine in memory formation: involvement in the memory enhancing effect of peripheral epinephrine. Chin J Physiol 38:88-91.

McCarty KD, De Vellis J (1979) The regulation of adenosine 3':5': 
cyclic monophosphate accumulation in glia by $\alpha$-adrenergic agonists. Life Sci 24:639-650.

McGaugh JL, Introini-Collison IB, Nagahara AH (1988) Memoryenhancing effects of posttraining naloxone: involvement of $\beta$-adrenergic influences in the amygdaloid complex. Brain Res 446:37-49.

McGaugh JL, Introini-Collison IB, Cahill L, Castellano C, Dalmaz C, Parent M, Williams C (1993) Neuromodulatory systems and memory storage: role of the amygdala. Behav Brain Res 58:81-90.

Parent MB, McGaugh JL (1994) Posttraining infusion of lidocaine into the amygdala basolateral complex impairs retention of inhibitory avoidance training. Brain Res 661:97-103.

Paxinos G, Watson C (1986) The rat brain in stereotaxic coordinates Ed 2. Sydney: Academic.

Perkins JP, Moore MM (1973) Characterization of the adrenergic receptors mediating a rise in cyclic $3^{\prime}, 5^{\prime}$-adenosine monophosphate in rat cerebral cortex. J Pharmacol Exp Ther 185:371-378.

Pfeuffer T (1977) GTP-binding proteins in membranes and the control of adenylate cyclase activity. J Biol Chem 252:7224-7234.

Pilc A, Enna SJ (1986) Activation of $\alpha_{2}$-adrenergic receptors augments neurotransmitter-stimulated cyclic AMP accumulation in rat brain cerebral cortical slices. J Pharmacol Exp Ther 237:725-730.

Puumala T, Greijus S, Narinen K, Haapalinna A, Riekkinen P Sr, Sirvio J (1998) Stimulation of $\alpha_{1}$-adrenergic receptors facilitates spatial learning in rats. Eur Neuropsychopharmacol 8:17-26.

Quirarte GL, Roozendaal B, McGaugh JL (1997) Glucocorticoid enhancement of memory storage involves noradrenergic activation in the basolateral amygdala. Proc Natl Acad Sci USA 94:14048-14053.

Rall TW, Sattin A (1970) The effect of adenosine and adenine nucleotides on the cyclic adenosine $3^{\prime}, 5^{\prime}$-phosphate content of guinea pig cerebral cortex slices. Mol Pharmacol 6:13-23.

Roozendaal B, McGaugh JL (1996) Amygdaloid nuclei lesions differentially affect glucocorticoid-induced memory enhancement in an inhibitory avoidance task. Neurobiol Learn Mem 65:1-8.

Roozendaal B, McGaugh JL (1997) Glucocorticoid receptor agonist and antagonist administration into the basolateral but not central amygdala modulates memory storage. Neurobiol Learn Mem 67:176-179.
Ross EM, Howlett AC, Ferguson KM, Gilman AG (1978) Reconstitution of hormone-sensitive adenylate cyclase activity with resolved components of the enzyme. J Biol Chem 253:6401-6412.

Salm AK, McCarthy KD (1992) The evidence for astrocytes as a target for central noradrenergic activity: expression of adrenergic receptors Brain Res Bull 29:265-275.

Schultz J, Daly JW (1973) Accumulation of cyclic adenosin 3',5'monophosphate in cerebral cortical slices from rat and mouse: stimulatory effect of $\alpha$ - and $\beta$-adrenergic agents and adenosine. J Neurochem 21:1319-1326.

Shain W, Forman DS, Madelain V, Turner JN (1987) Morphology and astroglial cells is controlled by $\beta$-adrenergic receptors. J Cell Biol 105:2307-2314.

Starke K (1979) Presynaptic regulation of catecholamines release in the central nervous system. In: The release of catecholamines from adrenergic neurons (Paton DM, ed), pp 143-183. New York: Pergamon.

Sternberg DB, Korol D, Novack GD, McGaugh JL (1986) Epinephrineinduced memory facilitation: attenuation by adrenoceptor antagonists. Eur J Pharmacol 129:189-193.

Stone EA, McEwen BS, Herrera AS, Carr KD (1987) Regulation of $\alpha$ and $\beta$ components of noradrenergic cyclic AMP response in cortical slices. Eur J Pharmacol 141:347-356.

Szabadi E (1978) Functionally opposite receptors on neurones. Life Sci 23:1890-1898.

Szabadi E (1979) Adrenoceptors on central neurones: microelectrophoretic studies. Neuropharmacology 18:831-843.

Szabadi E, Bradshaw CM (1974) The role of physical and biological factors in determining the time course of neuronal responses. Neuropharmacology 13:537-545.

Taussig R, Gilman AG (1995) Mammalian membrane-bound adenylyl cyclase. J Biol Chem 270:1-4.

U'Prichard DC, Reisine TD, Mason ST, Fibiger HC, Yamamura HI (1980) Modulation of rat brain $\alpha$ - and $\beta$-adrenergic receptor populations by lesion of the dorsal noradrenergic bundle. Brain Res 187: $143-154$. 